Research Article

\title{
Experimental Investigation of Mechanical Behavior of Sandstone with Different Moisture Contents Using the Acoustic Emission Technique
}

\author{
Chuanming Li, ${ }^{1,2}$ Nan Liu $\mathbb{D}^{1,2}$ and Wanrong Liu ${ }^{3}$ \\ ${ }^{1}$ School of Mining and Safety Engineering, Anhui University of Science and Technology, Huainan 232001, China \\ ${ }^{2}$ Key Laboratory of Coal Mine Safety and Efficiently Caving of Ministry of Education, \\ Anhui University of Science and Technology, Huainan 232001, China \\ ${ }^{3}$ Liaocheng University, Liaocheng 252059, China \\ Correspondence should be addressed to Nan Liu; ln3515@qq.com
}

Received 21 August 2020; Revised 27 October 2020; Accepted 23 November 2020; Published 9 December 2020

Academic Editor: Zhijie Wen

Copyright (C) 2020 Chuanming Li et al. This is an open access article distributed under the Creative Commons Attribution License, which permits unrestricted use, distribution, and reproduction in any medium, provided the original work is properly cited.

\begin{abstract}
The moisture content is a critical factor tightly related to rock deformation and its failure process since it leads to a significant change in the physicomechanical properties of rock during the underground engineering construction. As a result, engineering construction accidents take place frequently. To figure out the influence of the moisture content on the physicomechanical properties of water-bearing rock and then effectively avoid engineering accidents, multiple tests including the uniaxial compression test, Brazilian splitting test, and the acoustic emission (AE) test were carried out in this study. The experimental results showed that the water absorption rate of the sandstone gradually stabilizes after $5 \mathrm{~h}$, and its uniaxial compressive strength, tensile strength, and elastic modulus all decline with the increase of the moisture content. Compared to the dry state of the sample, the reduction amplitudes of the elastic modulus, compressive strength, and tensile strength of water-saturated rock samples can reach up to $27.3 \%, 35.2 \%$, and $38.1 \%$, respectively. It indicates that the tensile strength is more sensitive to the softening effect of the moisture. Through the AE test, it can be found that the internal state of water-saturated rock samples is greatly changed; the compressive strength of rock samples drops, so the rock can be damaged after absorbing less energy. Thus, moisture shows a certain softening effect on rock. The research results are expected to provide a basis for underground engineering construction and rock fracture and failure.
\end{abstract}

\section{Introduction}

How to safely, efficiently, environmental-friendly, and scientifically mine coal resources has been a research focus for scholars all over the world $[1,2]$. In the occurrence environment of rock involved in underground engineering, water is naturally existing, and rock deformation is generally related to the moisture content of the rock. Therefore, exploring the mechanical properties of rock on different moisture conditions is of engineering significance [3-6].

Many scholars have carried out studies on the influence of water on mechanical properties of rock. By conducting the loading and unloading tests on sandstone with different moisture contents, Pan et al. [7] analyzed the relationships of the moisture content with the compressive strength and elastic modulus of sandstone. Roy et al. [8] found that the tensile strength, Young's modulus, and fracture stiffness of rock all decline with increasing saturation degree by exploring the influence of different saturation times on the mechanical parameters of sandstone. Yu et al. [9] investigated the influence of water on the instantaneous and creep properties of red sandstone. They concluded that the increase in the moisture content corresponds to an exponential growth of the instantaneous strain and steady strain and a reduction of the creep strain and failure time of the samples. Yu et al. [10] reported the creep properties of silicarenite under different gradients of moisture contents. Zhou et al. [11] studied the effect of water injection on 
mechanical properties of hard strata and found that water injection can weaken the burst potential of strata through uniaxial compression tests. Cen et al. [12] performed the triaxial stress loading test on sandstone samples before and after being immersed in water. They suggested that the bonding force between sandstone particles reduces after there is a certain moisture content in sandstone, thus decreasing the deformation resistance of the sandstone.

Acoustic emission (AE) test is considered as an effective and efficient test method for detecting the internal state and mechanical properties of rock. As the precursory information on rock fracture and failure under compression, the $\mathrm{AE}$ phenomenon can be used in various geotechnical engineering fields such as coal mining, slope, tunnel, and bridge [13, 14]. For example, Mohanty et al. [15] explored the $\mathrm{AE}$ characteristics during failure and the determination method for fracture toughness of rock. By investigating the uniaxial compressive deformation and $\mathrm{AE}$ characteristics of rock, $\mathrm{Fu}$ [16] showed that the deformation rate of rock favorably corresponds to the occurrence frequency of $\mathrm{AE}$ events. Zhang et al. [17] carried out the test on AE characteristics of the fractured argillaceous siltstone with different moisture contents. The results showed that, due to the presence of the moisture content, the failure mode of argillaceous siltstone transits from sudden brittle failure to steady ductile failure. Verstrynge et al. [18] analyzed the influence of moisture on mechanical behaviors of sandstone by combining the AE-controlled creep test with the special multiscale method.

The aforementioned research results greatly improve our understanding of the evolution law of AE energy during rock failure. However, these studies basically aimed at dry rock and rock with different gradients of moisture contents while rarely involving natural and water-saturated rock. The majority of engineering rock is on moisture condition or at a water-saturated state during underground engineering construction. Therefore, this study carried out the uniaxial compression test, Brazilian splitting test, and AE test on rock samples on three typical moisture conditions (i.e., dry, natural, and water-saturated state) after selecting the typical sandstone. Exploring the influence of rock samples on moisture condition on mechanical properties of rock is expected to provide a guidance for underground engineering construction and rock failure in coal mines.

\section{Experimental Work}

2.1. Test Equipment and Sample Preparation. The RMT-150B rock mechanics test system in Anhui University of Science and Technology Laboratory was used for the test, which is controlled by a computer, is easy to operate, and has complete functions. Moreover, researchers can modify the control mode, test parameters, and test steps during the test.

The ADS5 AE system was selected to monitor the rock samples, which can collect signals by combining with a probe. Cai et al. [19] found that the AE frequency of rock generally ranges from 1 to $500 \mathrm{kHz}$. Therefore, to eliminate the influence of environmental noises on the $\mathrm{AE}$ test, the sampling frequency, threshold, and $A E$ sampling frequency of the preamplifier were, respectively, set as $40 \mathrm{~dB}, 50 \mathrm{~dB}$, and $1 \mathrm{kHz}-2 \mathrm{MHz}$ according to the previous tests. This set of $A E$ devices can collect data for various parameters including the number of $\mathrm{AE}$ events, energy, and arrival time. The test equipment is shown in Figure 1.

White sandstone was selected as the test sample owing to its favorable water absorption and uniform particles. According to the Suggested Method for Rock Mechanics Test, the rock samples were processed into rock cores with $\phi 50 \mathrm{~mm}$ by utilizing a laboratory SC-200core machine; afterwards, rock samples with the lengths of $L 100 \mathrm{~mm}$ and L25 $\mathrm{mm}$ were cut by applying a SCQ automatic stone cutting machine; and finally, rock samples were ground by employing a SCQM automatic cutting and grinding machine to ensure smoothness and evenness of two ends of the samples.

2.2. Test Scheme and Process. The loading test was conducted based on the slope wave control at the rate of $0.5 \mathrm{MPa} / \mathrm{s}$. It enabled more favorable cooperation with the AE system to control well the time synchronization of the RMT-150B rock mechanics test system and the AE monitoring system and a moderate amount of the collected $\mathrm{AE}$ information later. The AE probe was installed on the surface of the samples by utilizing the couplant before the test, and photos were taken during the test. In order to prepare the samples with different moisture contents, the specific test steps are shown as follows [20-22].

Table 1 displays different parameters of the tested samples. The Nos. $S 1 \sim S 9$ rock samples were weighed in the natural state, to take the mean $M_{1}$ after repeated weighing; the Nos. $S 1 \sim S 9$ rock samples were weighed repeatedly after being dried $48 \mathrm{~h}$ later in a constant-temperature $\left(100^{\circ} \mathrm{C}\right)$ drying oven. When the change of the mass was less than $0.01 \%$, it was considered that the rock sample had been completely dried. The mass $M_{2}$ of the dried specimens was then measured; and the specimen was wetted and maintained in a constant-humidity curing chamber to allow completed water absorption and to reach the preset mass. Meanwhile, the time required to reach the preset moisture content was recorded; subsequently, the rock samples were taken out and kept in a constant-temperature and constanthumidity curing chamber for $24 \mathrm{~h}$ to perform the test. As shown in Table 1 , the moisture content of the group of white sandstone $(S 4 \sim S 6)$ in the natural state is in the range of $0.202 \% \sim 0.231 \%$; the moisture content of the water-saturated rock samples $(S 7 \sim S 9)$ is in the range of $2.416 \% \sim$ $2.562 \%$; and due to the negligible error that appeared during the test, the rock samples were dried for $48 \mathrm{~h}$ at $100^{\circ} \mathrm{C}$, and it was thought that the moisture contents of dry rock samples $(S 1 \sim S 3)$ were $0 \%$. The moisture content $\omega$ was calculated according to:

$$
\omega=\frac{M_{1}-M_{2}}{M_{2}} \times 100 \%,
$$

where $M_{1}$ and $M_{2}$ refer to the mass of samples with natural moisture and that of dried samples, respectively. 

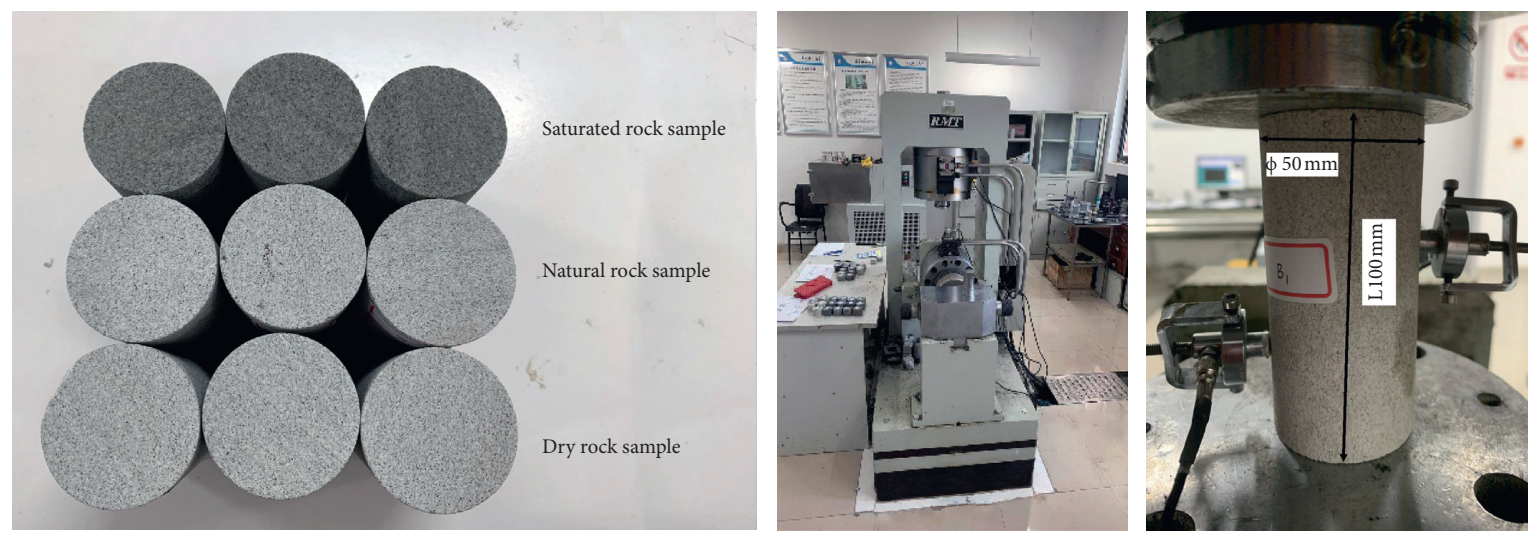

FIgURE 1: Sample preparation and the test equipment.

The change of the average moisture content of rock samples $(S 7 \sim S 9)$ with time is displayed in Figure 2. It can be seen that the moisture content of white sandstone with strong water absorbability rises with increasing wetting and water absorption time, while its water absorption rate, defined as the change of the water content by weight per unit time, greatly drops after $5 \mathrm{~h}$; the final moisture content stabilizes at $2.481 \%$. The fitting equation for the moisture content and wetting time of rock samples is shown in Equation (2), with the correlation coefficient $R^{2}=0.9890$. The red curve in Figure 2 represents the fitting equation, which is only applicable for the selected white sandstone with $\phi 50 \mathrm{~mm}$ and $L 100 \mathrm{~mm}$ during the test. The fitting equation possibly varies when the dimension and type of rock samples are changed:

$$
y=-0.0232 e^{(-t / 1.6278)}+3.6241 e^{(-t / 0.1314)}+0.02549 .
$$

In the complete process from the uniaxial compressive deformation to the failure of rock, the compression machine was operated always synchronously with the AE system. The system was capable of automatically collecting data; the stress, strain, and time were recorded to draw the stressstrain and displacement-loading curves; moreover, the $\mathrm{AE}$ system could automatically record the number of $\mathrm{AE}$ events.

\section{Analysis of Test Results}

3.1. Analysis of the Compressive Strength. Figure 3 shows the stress-strain curves of rock samples on different moisture conditions. By comparing the results through parallel tests, it can be found that the stress-strain curves of rock samples in the dry $(S 1 \sim S 3)$, natural $(S 4 \sim S 6)$, and water-saturated $(S 7 \sim S 9)$ states exhibit a favorable similarity. Considering that a difference is shown among rock samples, the postpeak stress-strain curves during the test present a difference under the same moisture conditions. With the growing moisture content of the samples, the peak strength and the peak strain of the samples decline. In this case, the fracture compaction stage is greatly prolongated. As for all rock samples, the stress rises, and the stress-strain curves partly approximately linearly vary (that is, the samples are in an elastic deformation stage within the range) after fracture compaction for a short time during loading; moreover, after reaching the peak, the stress of all samples rapidly and linearly drops to $0 \mathrm{MPa}$, suggesting that the samples on different moisture conditions all immediately lose the bearing capacity after the samples are damaged. The possible reason is that the moisture in rock samples shows a certain softening effect on mechanical properties of rock, which tends to undergo the creep deformation. Water molecules flow into pores between particles to wet the particles and cements, and therefore the extent of deformation and failure of the water-saturated rock samples is lower than that of dry rock samples. If the force applied by the testing machine is larger than the bearing capacity of rock samples, the cohesion strength of the particle cementation fails. In this case, rock failure appears because the cohesion of rock samples cannot resist the externally applied load [23]. The debris is generated during rock failure, making a light sound, and rock samples lose the bearing capacity because they cannot keep in the original state.

As shown in Figure 4, the mean values of the maximum compressive strengths and elastic moduli of dry rock samples are $55.167 \mathrm{MPa}$ and $5.409 \mathrm{GPa}$; the two parameters in the natural state are $54.783 \mathrm{MPa}$ and $5.461 \mathrm{GPa}$; and the two values in the water-saturated state are $35.762 \mathrm{MPa}$ and $3.935 \mathrm{GPa}$, respectively. The moisture content of rock samples in the natural state is $0.202 \%$ (lower than $1 \%$ ), which basically approximates to that in the dry state. There is a slight difference between rock samples in the two states in terms of the elastic modulus and compressive strength. The elastic modulus and compressive strength of water-saturated rock samples both decline, showing the reduction amplitudes of $27.3 \%$ and $35.2 \%$ compared with those in the dry state. It can be seen that moisture content can remarkably affect the mechanical properties of rock samples and the final rock fracture and failure [20, 24].

Jia, Cai [25-27] thought that water presence lowers the elastic limit of rock by softening the rock, and the moisture in rock mainly appears as free water and bound water. On one hand, rock experiences the damage effect by free water: free water poses the pore water pressure on rock under the gravitational effect and thus, the tip of microcracks in rock is 
TABle 1: Physical parameters of rock samples in different states.

\begin{tabular}{lcccc}
\hline Serial number & Dry weight $(\mathrm{g})$ & Wet weight $(\mathrm{g})$ & Moisture content $\omega(\%)$ & Average moisture content $\omega(\%)$ \\
\hline S1 & 471.61 & - & 0 & 0 \\
S2 & 462.82 & - & 0 & 0 \\
S3 & 470.36 & - & 0.202 & 0.215 \\
S4 & 470.61 & 471.56 & 0.214 & 0.231 \\
S5 & 472.62 & 471.98 & 2.461 & 2.481 \\
S6 & 470.86 & 483.82 & 2.418 & 2.562 \\
S7 & 473.21 & 484.18 & 483.25 & \\
S8 & 473.71 & 472.19 & &
\end{tabular}

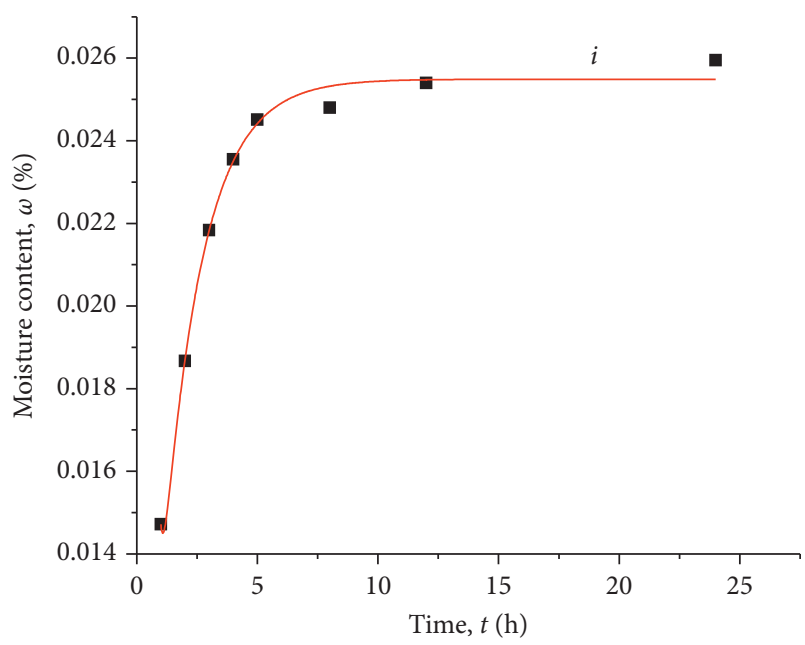

FIgURE 2: Relationship between the average moisture content and the wetting time.

subjected to the tensile stress; on the other hand, rock samples undergo the damage effect by bound water: the bound water can be adsorbed onto the surface of mineral particles in rock to decompose cements between particles, thus directly leading to the reduction of the friction force between mineral particles and further decrease of rock strength. Therefore, the moisture in rock induces the reduction of the rock strength and aggravates the damage capacity under the loading effect.

3.2. Analysis of the Tensile Strength. The standard rock samples with $\phi 50 \mathrm{~mm}$ and $\mathrm{L} 25 \mathrm{~cm}$ were used for the splitting test, in which $a 1, a 2$, and $a 3$ corresponded to the dry rock samples; $b 1, b 2$, and $b 3$ denoted the natural rock samples, and $c 1, c 2$, and $c 3$ represented those containing moisture. The RMT-150B rock mechanics test system was employed to load the rock samples based on slope wave control. Since the splitting test speed was fast, the loading rates were all set as $0.2 \mathrm{MPa} / \mathrm{s}$.

As shown in Figure 5, the tensile strength of white sandstone reduces with the growth of the moisture content, which is basically coincident with the change trend of the uniaxial compressive strength. The means of the tensile strengths of rock samples in the dry, natural, and watersaturated states are $3.471,3.168$, and $2.153 \mathrm{MPa}$, respectively. Compared to the dry state, the tensile strength of water- saturated rock samples reduces by $38.1 \%$. In the initial loading stage during the test, the stress rapidly grows, while the strain basically remains unchanged, indicating that the rock samples are stressed to absorb energy in the initial stage; after the energy reaches a certain level, rock samples are fractured within a short time; when the rock samples cannot bear the loading effect of the external force, the splitting failure occurs at the middle part of rock samples along the loading direction; in this context, the stress rapidly drops. It can be clearly seen from the figure that the rock samples at different states show a same rise section in the stress-strain growth stage, implying that the rock samples with different moisture contents all reflect the mechanical properties thereof.

The attenuation of the compressive strength and tensile strength of rock samples after absorbing water reflects the softening effect of water on rock structures at different directions, so the concept of the softening coefficient is introduced [21]. The softening coefficient reflects the change of the mechanical strength of rock before and after water absorption treatment and engineering geological properties of rock. Generally, under $K_{C / T}>0.75$, the softening performance is poor, and the engineering performance is favorable. The softening coefficient is calculated according to the following equation:

$$
K_{C / T}=\frac{\sigma_{s}}{\sigma_{d}}
$$

where $K_{C}$ and $K_{T}$ refer to the compressive and tensile softening coefficients of rock; $\sigma_{d}$ and $\sigma_{s}$ denote the compressive and tensile strength ( $\mathrm{MPa}$ ) of the rock samples, respectively.

According to Equation (3), it can be calculated that $K_{C}=0.987$ and $K_{T}=0.912$ for rock samples in the natural state, while $K_{C}=0.648$ and $K_{T}=0.621$ for water-saturated rock samples. It can be found that $K_{T}$ is lower than $K_{C}$ for rock samples both in the natural and water-saturated states, which indicates that the tensile strength is more sensitive to the softening effect of water. It can be also verified based on the reduction amplitude of the compressive and tensile strengths of rock samples in the water-saturated state relative to those in the dry state.

3.3. Analysis of Failure Modes of Rock. Figure 6 shows the failure modes of the samples ( $S 2, S 4$, and $S 8$ ) from the same rock block on different moisture conditions. The mean value 


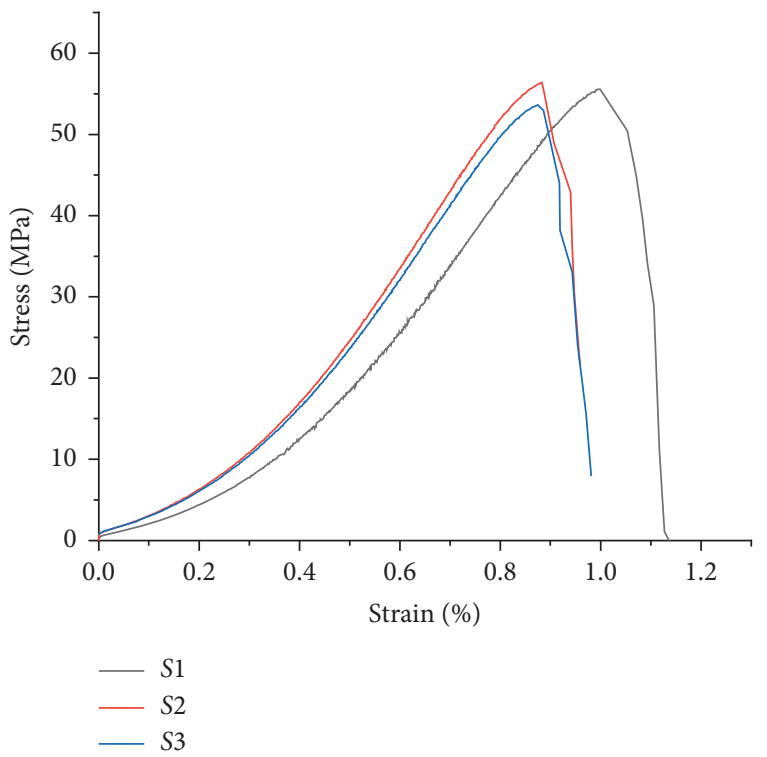

(a)

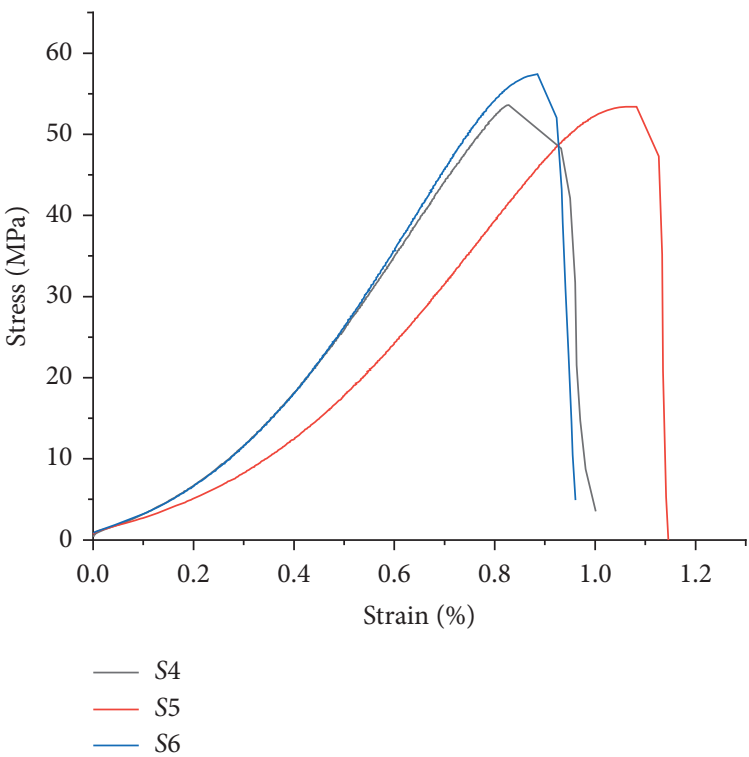

(b)

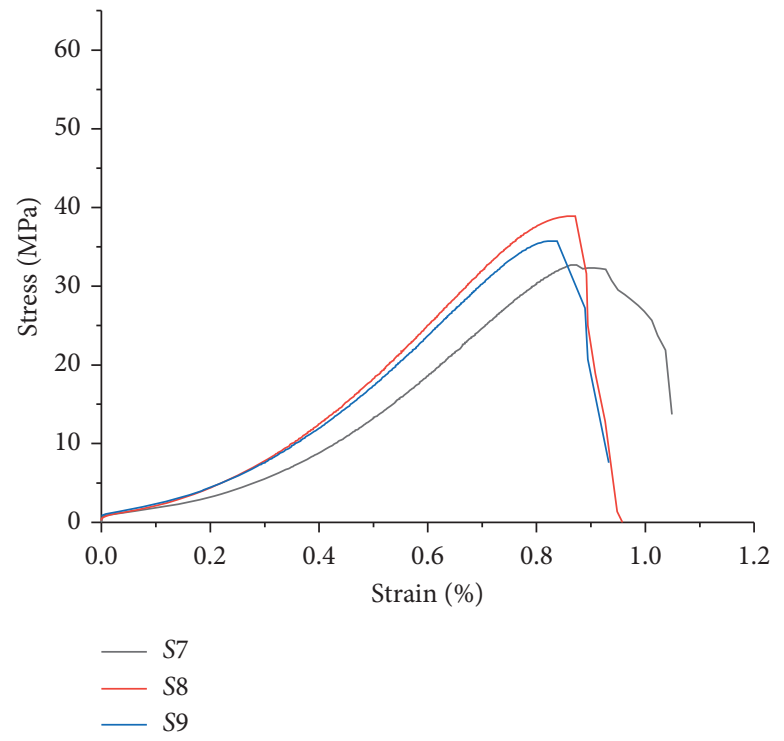

(c)

FiguRE 3: Stress-strain curves of rock samples on different moisture conditions under the uniaxial compression. (a) Dry state. (b) Natural state. (c) Water-saturated state.

of the compressive strengths of the rock sample in the dry state is $55.167 \mathrm{MPa}$; and like other brittle rocks, X-shaped conjugated and inclined planes can be observed, which means that the sample was broken under shear stress. After being damaged, the sample is fractured into 3-6 large rock blocks, together with a few fragments. However, the mean compressive strength of the rock samples in the natural state slightly decreases, and the rocks undergo a combined failure of shear and tensile stress. $X$-shaped conjugated and inclined planes imply the dominated role of the shear stress in rock failure, but the vertical fractures suggest that the tensile stress also takes a part. The mean of the compressive strengths of the water-saturated rock sample is $35.762 \mathrm{MPa}$. The rock sample is relatively broken after loading. The damaged rock sample is crushed into many small rock blocks, being relatively broken. The water-saturated rock sample also experiences a combined failure: dominated by tensile failure, together with shear failure appearing as $X$ shaped conjugated and inclined planes. During the test, rock samples on three different moisture conditions all do not show significant precursor information on failure.

It can be seen that the failure mode of rock samples becomes more complex gradually with increasing moisture content of rock samples. Under the effect of moisture, the compressive strength decreases, and Poisson's ratio rises; furthermore, the lateral deformation of rock samples is strengthened. On this condition, the failure mode of the rock samples progressively varies from the dominated $X$-shaped 


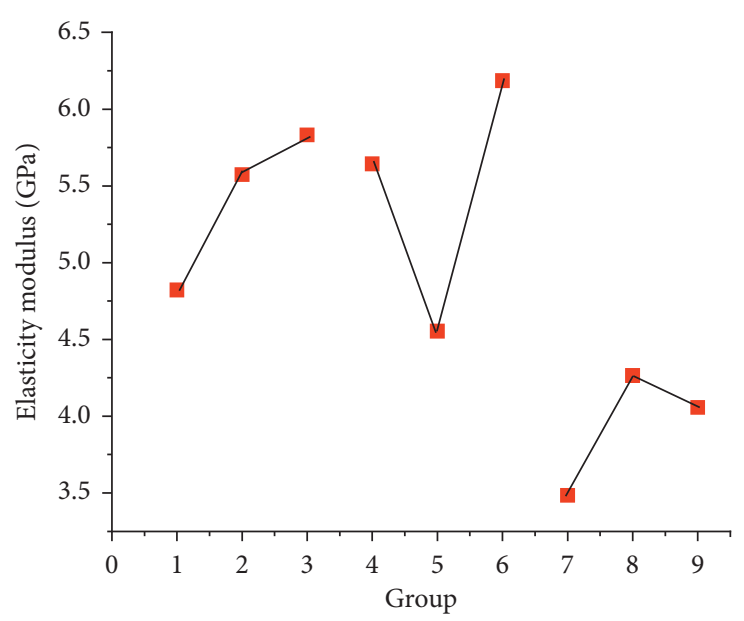

(a)

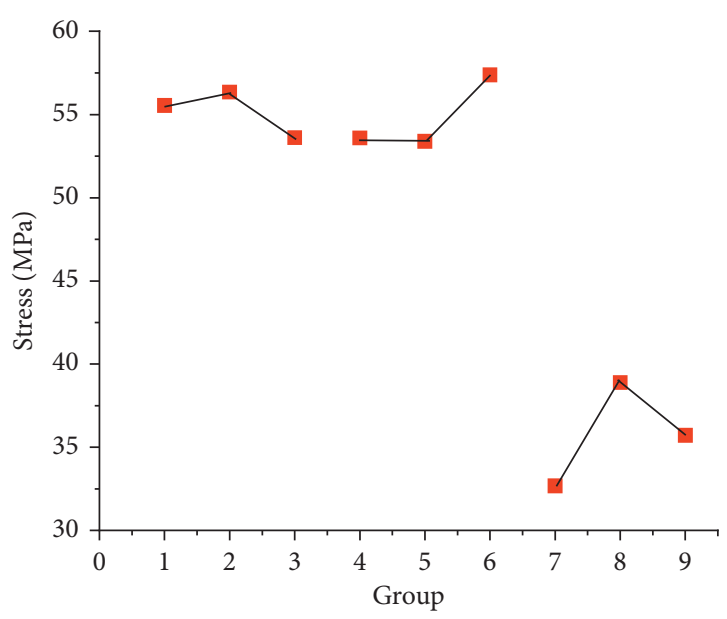

(b)

Figure 4: Scatter diagrams of the elastic modulus and maximum stress on rock samples on different moisture conditions. (a) Scatter diagram of elastic modulus. (b) Scatter diagram of the maximum stress.

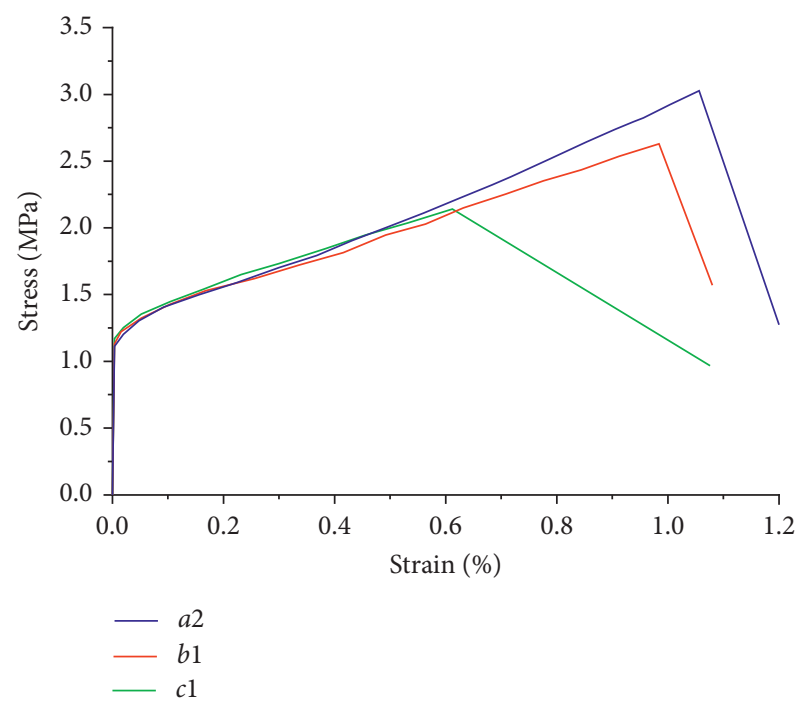

FIGURE 5: Stress-strain curves of rock samples on different moisture conditions during Brazilian splitting test.

shear failure to the combined tensile and shear failure. At a high moisture content, the rock samples are greatly deformed and complexly stressed. After rock failure, many complex cracks occur. During the Brazilian splitting test, the rock samples in the three states are all damaged from the central plane along the loading direction and further, they are crushed into two rock blocks. However, the tensile strength of the rock samples in the water-saturated state is significantly lower than that in the other two states, which further reveals the softening effect of water on rock. The failure modes of rock samples during the Brazilian splitting test are displayed in Figure 7.

3.4. AE Characteristics of Rock with Different Moisture Contents. The failure process of rock under the loading effect actually corresponds to the coupling process between energy absorption and energy release. The ratio of $\mathrm{AE}$ events and the cumulative number of $\mathrm{AE}$ events can indicate the formation, extension frequency, and total number of cracks in sandstone $[14,28]$. According to the data collected by using the DS5 AE detection system, the change curves of the total energy and cumulative AE events in rock samples on different moisture conditions with time are drawn. The curves concerning $S 3, S 5$, and $S 8$ are selected as those of rock samples in the dry, natural, and water-saturated states. Scholars have suggested that types of $\mathrm{AE}$ sources during failure of materials mainly include shear, tensile, and tensileshear fractures [29-32]. AE characteristics vary under different fracture types during rock failure.

The stress-strain-cumulative energy-ringing count curves of rock samples are shown in Figure 8. According to the relationships among various curves in the figure, the stress-strain-cumulative energy-ring-down count curves can be divided into five stages, corresponding to $\mathrm{OA}, \mathrm{AB}, \mathrm{BC}$, $\mathrm{CD}$, and failure stage after the point $D$ [33-35], in which point $\mathrm{O}$ is considered as the initial point. Point $A$ is taken as a significant inflection point of the curves of the uniaxial compression process and the cumulative $\mathrm{AE}$ energy in rock samples. Point B is an inflection point of the cumulative energy from steady change to growth. Point $C$ is an inflection point where the cumulative energy dramatically rises and the ring-down count of rock samples significantly occurs, and point $D$ corresponds to the peaks of the compressive strength, cumulative energy, and ring-down count of rock samples.

With the test process, the ring-down count and the cumulative energy within BD gradually rise and further, the deformation rate greatly increases. It can be seen from the image that new microfractures start to occur in rock samples with the growth of the axial load applied by the loading machine. In this stage, $\mathrm{AE}$ signals are strong, and the ringdown counts are high, also having high energy, especially after point $C$. Moreover, the ring-down counts are basically distributed within the section and reach a peak at point $D$. It 


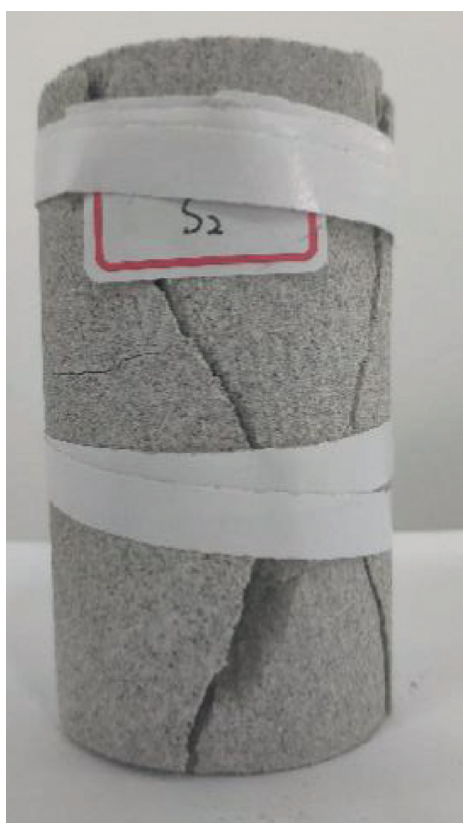

(a)

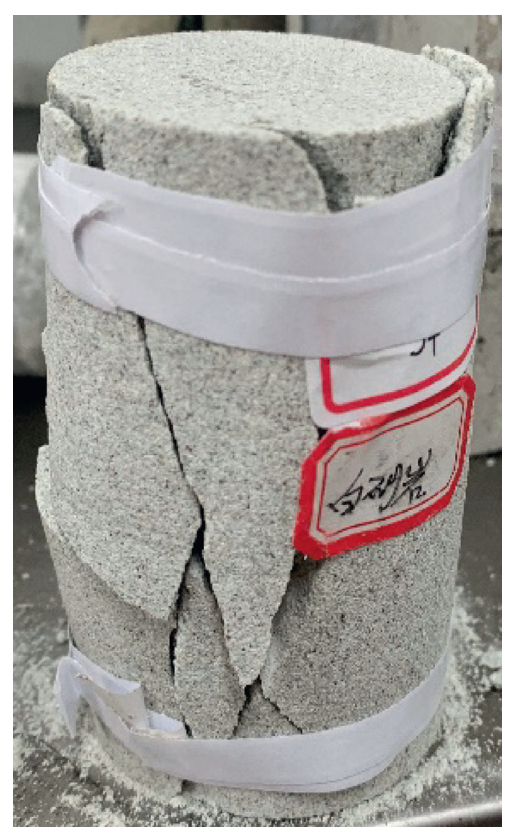

(b)

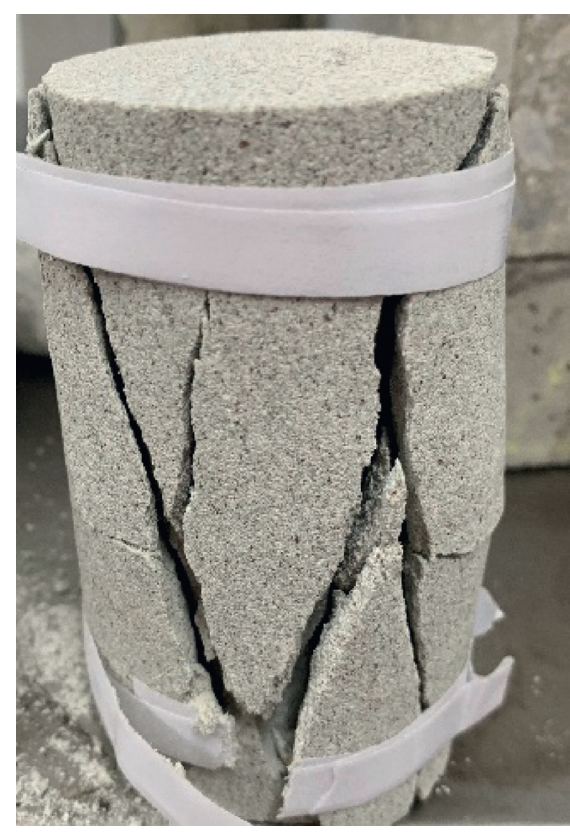

(c)

FIGURE 6: Macroscopic failure modes of rock samples on different moisture conditions during the uniaxial compression test. (a) Dry state. (b) Natural state. (c) Water-saturated state.

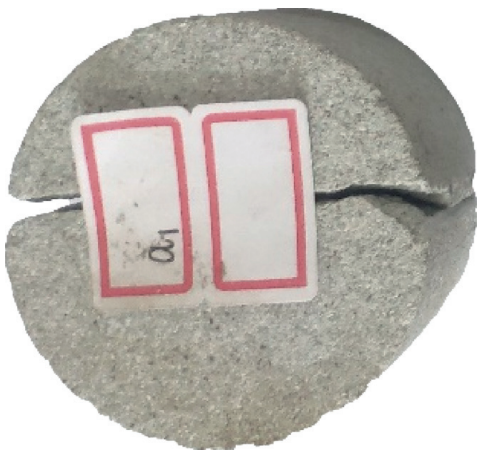

(a)

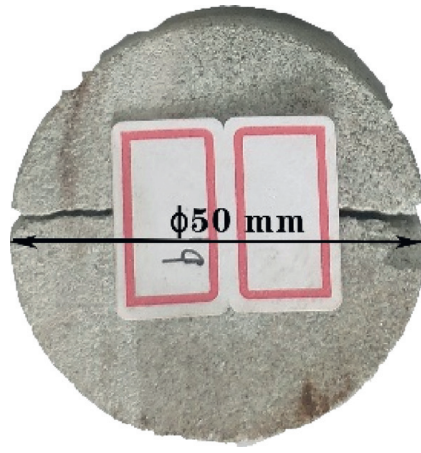

(b)

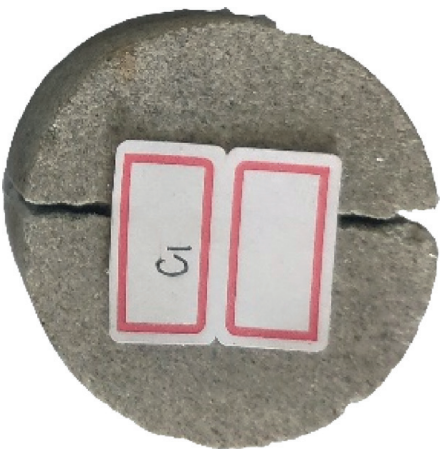

(c)

FIGURE 7: Macroscopic failure modes of rock samples on different moisture conditions during the Brazilian splitting test.

indicates that the samples are in a critical state, that is, the instable and propagation of cracks to fracture failure. There are basically no energy release and generation of ring-down counts after point $D$, implying that the rock samples have been completely damaged.

It can be seen from Figure 8(a) that the axial strain ranges of sections $\mathrm{AB}$ and $\mathrm{BD}$ of dry rock samples are $0.04 \times 10^{-2} \sim$ $0.38 \times 10^{-2}$ and $0.38 \times 10^{-2} \sim 0.87 \times 10^{-2}$, in which the corresponding axial strains at point $\mathrm{C}$ and in sections $\mathrm{AB}$, $\mathrm{BC}$, and $\mathrm{CD}$ are $0.75 \times 10^{-2}, 0.34 \times 10^{-2}, 0.37 \times 10^{-2}$ and $0.12 \times 10^{-2}$, respectively. The peaks of the ring-down counts and the cumulative energy are 2458 and $1674597.85 \mathrm{mV} \times \mathrm{mS}$, respectively. In this context, the compressive strength of rock samples is $53.608 \mathrm{MPa}$.
As shown in Figure $8(\mathrm{~b})$, the axial strain ranges of sections $\mathrm{AB}$ and $\mathrm{BD}$ of the natural rock samples are $0.2 \times$ $10^{-2} \sim 0.48 \times 10^{-2}$ and $0.48 \times 10^{-2} \sim 0.88 \times 10^{-2}$, in which the corresponding axial strains at point $\mathrm{C}$ and in sections $\mathrm{AB}, \mathrm{BC}$, and $\mathrm{CD}$ are $0.72 \times 10^{-2}, 0.28 \times 10^{-2}$, $0.24 \times 10^{-2}$ and $0.16 \times 10^{-2}$, respectively. The peaks of the ring-down counts and the cumulative energy are 1688 and $1888748.7 \mathrm{mV} \times \mathrm{mS}$, respectively. On this condition, the compressive strength of rock samples is $53.384 \mathrm{MPa}$.

As shown in Figure 8(c), it can be found that the axial strain ranges of sections $\mathrm{AB}$ and $\mathrm{BD}$ of water-saturated rock samples are $0.10 \times 10^{-2} \sim 0.70 \times 10^{-2}$ and $0.70 \times 10^{-2} \sim$ $0.86 \times 10^{-2}$, respectively, in which the corresponding axial strains at point $\mathrm{C}$ and in sections $\mathrm{AB}, \mathrm{BC}$, and $\mathrm{CD}$ are 


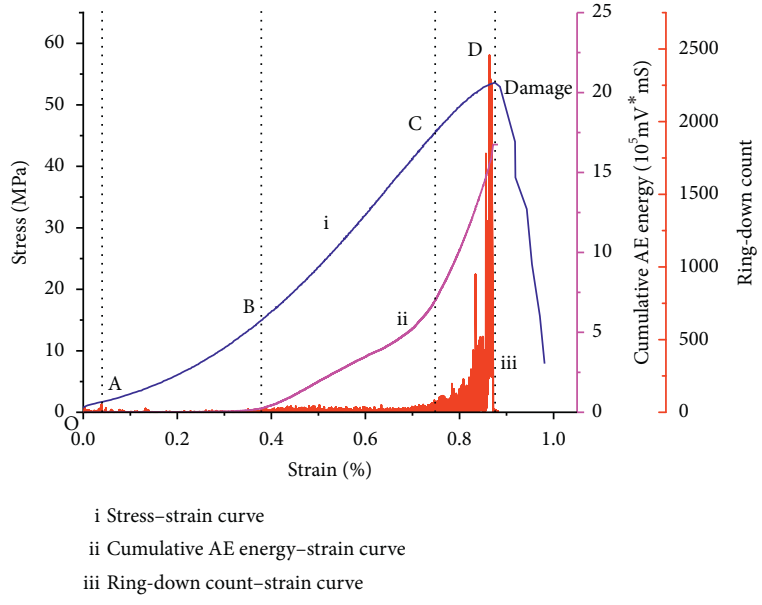

(a)

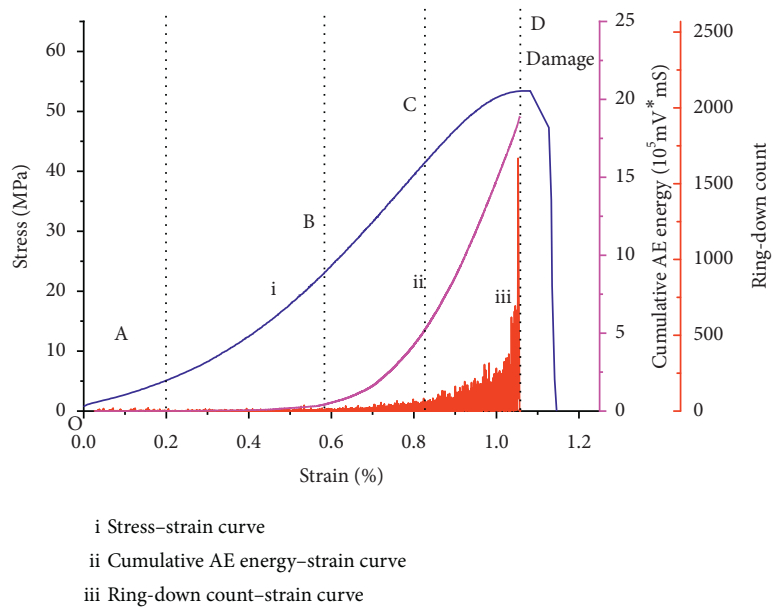

(b)

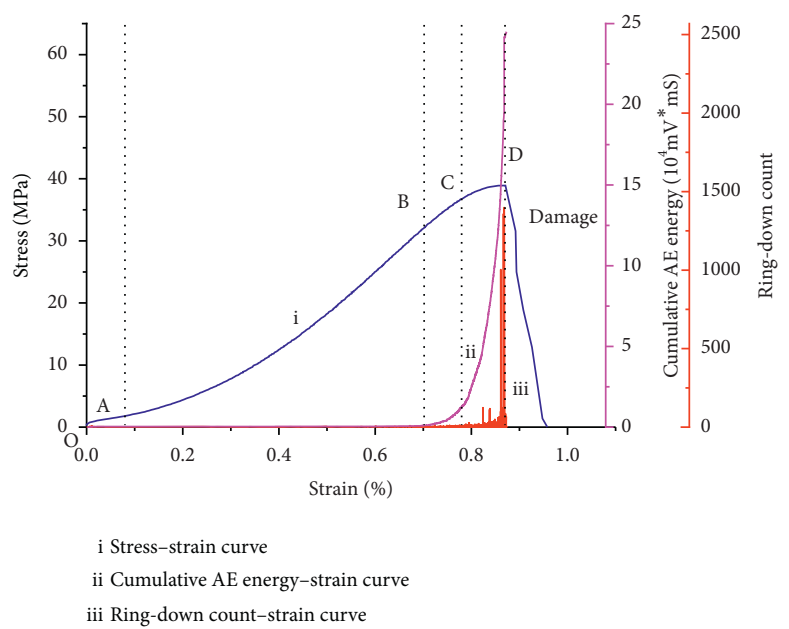

(c)

FIGURE 8: Stress-strain-cumulative energy-ring-down count curves of rock samples in different states. (a) Dry state. (b) Natural state. (c) Water-saturated state.

$0.72 \times 10^{-2}, 0.6 \times 10^{-2}, 0.12 \times 10^{-2}$ and $0.04 \times 10^{-2}$, respectively. The peaks of the ring-down counts and cumulative energy are 1398 and $244737.6 \mathrm{mV} \times \mathrm{mS}$, respectively. In this case, the compressive strength of rock samples is 38.890 MPa.

By comparing and analyzing the AE diagram of rock samples at the three states during uniaxial compression, it can be seen that, in the initial test stage (section OA), a few ring-down counts are generated in dry and natural rock samples, while ring-down counts are hardly found in the water-saturated rock samples. In section $\mathrm{AB}$ during the test, there are a small number of ring-down counts and low cumulative energy. The section length of natural rock samples is $18 \%$ and $54 \%$ shorter than that of dry and watersaturated rock samples, respectively; within section $\mathrm{BC}$, the ring-down counts and cumulative energy gradually rise, and the deformation rate greatly increases. The section length of natural rock samples is $36 \%$ shorter than that of dry rock samples, while it is $50 \%$ longer than that of water-saturated rock samples. In section $\mathrm{CD}$, the ring-down counts and cumulative energy gradually grow and further, the deformation rate significantly increases. The section length of natural rock samples is $25 \%$ and $75 \%$ longer than that of dry and water-saturated rock samples, respectively. In this context, the cumulative energy peak of the moisture-saturated sample is more than 10 times lower than both of the natural and dry rock samples. The peaks and total counts of the moisture-saturated rock samples in each stage are all lower than those of dry rock samples; and the ring-down count of the water-saturated samples is sparsely distributed with time series. Zang et al. [36, 37] thought that fewer microfractures are generated in rock samples on moisture condition during uniaxial compression process and therefore, the absorbed heat is less. It can be concluded that the moisture in rock samples will greatly change the internal state of rock samples to lower their compressive strength; 
and the rock failure occurs after absorbing less energy. Moisture shows a certain softening effect on the rock to some extent.

\section{Conclusions}

The compressive strength, tensile strength, and elastic modulus are three important mechanical parameters when conducting underground activities including underground excavation, tunneling support, and mineral ore mining. However, the influence of the moisture content has long been ignored, leading to serious hazard potential. In this study, the uniaxial compression test, Brazilian splitting test, and $\mathrm{AE}$ test were carried out on white sandstone on different moisture conditions. And also, the influence of the moisture content on the uniaxial compressive strength, tensile strength, failure modes, and AE signals was analyzed. The following conclusions are drawn:

(1) With the growth of the moisture content, the fracture compaction stage in the stress-strain curve of rock samples increases. The elastic modulus and compressive strength of rock samples at the water-saturated state both decline, showing reduction amplitudes of $27.3 \%$ and $35.2 \%$ relative to those of dry rock samples; in addition, the tensile strength of the water-saturated rock samples presents a reduction amplitude of $38.1 \%$ compared with that of the dry rock samples.

(2) Water also exhibits a certain influence on deformation characteristics of rock samples. The dry rock samples undergo the shear failure appearing as occurrence of $X$-shaped conjugated inclined plane; the natural rock samples are subjected to a combined failure: dominated by shear failure appearing as occurrence of $X$-shaped conjugated inclined planes, accompanying with tensile failure. Owing to the presence of water that will reduce the elastic limit of rock and soften the rock, the water-saturated rock samples mainly experience the tensile failure, accompanying the shear failure appearing as the occurrence of $X$-shaped conjugated inclined planes.

(3) Water greatly influences the AE characteristic parameters of rock samples. In the initial loading stage (section $\mathrm{OA}$ ), AE signals hardly occur in the dry, natural, and water-saturated rock samples. After developing to section $A B$, there are a small number of ring-down counts and low cumulative energy; in section $\mathrm{BD}$, the ring-down counts and cumulative energy gradually increase, and the rock is damaged after reaching the peak at point $D$. The deformation rate greatly rises. The peaks and total counts of water-saturated rock samples in each stage are all lower than those of dry rock samples; the ring-down counts of water-saturated rock samples are sparsely distributed with time series. Water-saturated rock samples are damaged after absorbing less energy. It indicates that the moisture presents a softening effect on the rock to some extent.

\section{Data Availability}

The data used to support the findings of this study are available from the corresponding author upon request.

\section{Conflicts of Interest}

The authors declare that they have no conflicts of interest.

\section{Authors' Contributions}

Chuanming Li and Wanrong Liu designed the experiments; Nan Liu carried out the experiments; Nan Liu and Chuanming Li analyzed the experimental results; Nan Liu and Wanrong Liu wrote the manuscript.

\section{Acknowledgments}

This research was supported by the Anhui Provincial Natural Science Foundation (2008085ME147).

\section{References}

[1] H. P. Xie, F. Gao, Y. Ju et al., "Theoretical and technological conception of the fluidization mining for deep coal resources," Journal of China Coal Society, vol. 42, no. 3, pp. 547-556, 2017.

[2] C. Robert, M., M. Romeo, M. Flores, and D. Gary Stricker, "Coal Resources, Reserves and Peak Coal Production in the United States," International Journal of Coal Geology, vol. 113, pp. 109-115, 2013.

[3] X. R. Liu, Y. Fu, Y. R. Zheng, and N. H. Liang, "A review on deterioration of rock caused by water-rock interaction," Chinese Journal of Underground Space And Engineering, vol. 8, no. 1, pp. 77-82, 2012.

[4] J. D. Jiang, S. S. Chen, J. Xu, and Q. S. Liu, "Mechanical properties and energy characteristics of mudstone under different containing moisture states," Journal of China Coal Society, vol. 43, no. 8, pp. 2217-2224, 2012.

[5] J. Bao, J. S. Tsau, and R. Barati, "A workflow to estimate shale gas permeability variations during the production process," Flue, vol. 220, pp. 879-889, 2018.

[6] J. Bao, J. S. Tsau, and B. Reza, "Investigation of shale-gasproduction behavior: evaluation of the effects of multiple physics on the matrix," SPE Reservoir Evaluation and Engineering, vol. 23, no. 1, 2020.

[7] Z. J. Pan, L. D. Connell, M. Camilleri, and L. Connelly, "Effects of matrix moisture on gas diffusion and flow in coal," Fuel, vol. 89 , no. $11,2010$.

[8] D. G. Roy, T. N. Singh, J. Kodikara, and D. Ratan, "Effect of water saturation on the fracture and mechanical properties of sedimentary rocks," Rock Mechanics and Rock Engineering, vol. 50, no. 10, pp. 2585-2600, 2017.

[9] C. Y. Yu, S. B. Tang, and C. A. T, "Experimental investigation on the effect of water content on the short-term and creep mechanical behaviors of red sandstone," Journal of China Coal Society, vol. 44, no. 2, pp. 473-481, 2019.

[10] X. B. Yu, F. Chen, and T. Q. Lin, "Mechanical property and creep behavior of quartz sandstone under dry and saturated states," Water Resources and Power, vol. 37, no. 6, pp. 121-123, 2019.

[11] H. C. Zhou, C. Z. Jia, and H. F. Jiang, "Study on impact tendency of water injection on hard rock," Inner Mongolia Coal Economy, no. 10, pp. 127-147, 2018. 
[12] C. Z. Cen, Y. F. Jiang, and C. J. Jiang, "Experiment and analysis about the change of elasticity modulus of coal with different water contained," Value Engineering, vol. 34, no. 24, pp. 154-155, 2015.

[13] A. Lavrov, "The kaiser effect in rocks: principles and stress estimation techniques," International Journal of Rock Mechanics and Mining Sciences, vol. 40, no. 2, 2015.

[14] V. Rudajev, J. Vilhelm, and T. Lokajicek, "Laboratory studies of acoustic emission prior to uniaxial compressive rock failure," International Journal of Rock Mechanics and Mining Sciences, vol. 37, no. 4, 2000.

[15] M. H. B. Nasseri, B. Mohanty, and R. P. Young, "Fracture toughness measurements and acoustic emission activity in brittle rocks," Pure and Applied Geophysics, vol. 163, no. 5-6, pp. 917-945, 2006.

[16] X. M. Fu, "“Experimental study on uniaxial compression deformation and acoustic emission proerty of typical rocks," Journal of Chengdu University of Technology (Science and Technology Edition), no. 1, pp. 17-21, 2005.

[17] A. B. Zhang, X. X. Liu, Y. B. Zhang, and B. Z. Zhu, "Experimental research on acoustic emission characteristics of argillaceous siltstone failure under different moisture contents," Chinese Journal of Underground Space and Engineering, vol. 13, no. 3, pp. 591-597, 2017.

[18] E. Verstrynge, L. Schueremans, D. V. Gemert, and M. Wevers, "Monitoring and predicting masonry's creep failure with the acoustic emission technique," NDT and E International, vol. 42, no. 6, 2009.

[19] M. Cai, H. Morioka, P. K. Kaiser et al., "Back-analysis of rock mass strength parameters using ae monitoring data," International Journal of Rock Mechanics and Mining Sciences, vol. 44, no. 3, 2006.

[20] W. D. Liu, X. Zhu, Q. Xu et al., "Acoustic emission of rock and its fractal feature under uniaxial compression," Water Resources and Hydropower Engineering, vol. 28, no. 9, pp. 181185, 2017.

[21] T. B. Li, Z. Q. Chen, G. Q. Chen et al., "An experimental study of energy mechanism of sandstone with different moisture contents," Rock and Soil Mechanics, vol. 36, no. S2, pp. 229-236, 2015.

[22] X. Cai, Z. L. Zhou, L. H. Tan et al., "Fracture behavior and damage mechanisms of sandstone subjected to wetting-drying cycles," Engineering Fracture Mechanics, vol. 234, 2020.

[23] B. Vasarhelyi and P. Van, "Influence of water content on the strength of rock," Engineering Geology, vol. 84, no. 1, 2005.

[24] X. Cai, Z. L. Zhou, L. H. Tan et al., "Water saturation effects on thermal infrared radiation features of rock materials during deformation and fracturing," Rock Mechanics and Rock Engineering, vol. 53, no. 11, pp. 4839-4856, 2020.

[25] H. L. Jia, T. Wang, W. Xiang et al., "Influence of water content on the physical and mechanical behaviour of argillaceous siltstone and some microscopic explanations," Chinese Journal of Rock Mechanics and Engineering, vol. 37, no. 7, pp. 1618-1628, 2018.

[26] X. Cai, Z. L. Zhou, H. Z. Zang et al., "Water saturation effects on dynamic behavior and microstructure damage of sandstone : phenomena and mechanisms," Engineering Geology, vol. 276, 2020.

[27] X. Cai, Z. L. Zhou, X. M. Du et al., "Water-induced variations in dynamic behavior and failure characteristics of sandstone subjected to simulated geo-stress," International Journal of Rock Mechanics and Mining Sciences, vol. 130, 2020.

[28] J. Y. Jiang, W. Zheng, and K. Tao, "Rock moisture recognition by combining AE with musical-staff-inspired model,"
International Conference on Humanities and Social Science Research, pp. 19-24, 2016.

[29] J. L. Miao, M. C. He, D. J. Li et al., "Acoustic emission characteristics of granite under strain rock burst test and its micro-fracture mechanism," Chinese Journal of Rock Mechanics and Engineering, vol. 28, no. 8, pp. 1593-1603, 2009.

[30] P. Li, F. H. Ren, M. F. Cai, Q. F. Guo et al., "Investigating the mechanical and acoustic emission characteristics of brittle failure around a circular opening under uniaxial loading," International Journal of Minerals Metallurgy and Materials, vol. 26, no. 10, pp. 1217-1230, 2019.

[31] T. Shiotani, M. Ohtsu, and K. Ikeda, "Detection and evaluation of AE," Waves Due to Rock Deformation," Construction and Building Materials, vol. 12, no. 02, 2001.

[32] J. P. Liu, R. Wang, G. Lei, and Y. T. Si, "Studies of stress and displacement distribution and the evolution law during rock failure process based on acoustic emission and microseismic monitoring," International Journal of Rock Mechanics and Mining Sciences, vol. 132, 2020.

[33] Y. L. Chen, Z. A. Wei, J. Xu et al., "Experimental research on the acoustic emission characteristics of rock under uniaxial compression," Journal of China Coal Society, vol. 36, no. S2, pp. 237-240, 2011.

[34] Y. Yan, "Experimental study on acoustic emission characteristics of rock under uniaxial compression," Journal of Hubei University of Technology, vol. 33, no. 2, pp. 103-107, 2018.

[35] P. Rodríguez and T. B. Celestino, "Application of acoustic emission monitoring and signal analysis to the qualitative and quantitative characterization of the fracturing process in rocks," Engineering Fracture Mechanics, vol. 210, 2019.

[36] A. Zang, C. F. Wagner, and G. Dresen, "Acoustic emission, microstructure, and damage model of dry and wet sandstone stressed to failure," Journal of Geophysical Research: Solid Earth, vol. 101, no. B8, pp. 17507-17521, 1996.

[37] Z. Liu, Q. G. Yao, B. Kong, and J. L. Yin, "Macro-micro mechanical properties of building sandstone under different thermal damage conditions and thermal stability evaluation using acoustic emission technology," Construction and Building Materials, vol. 246, 2020. 